\title{
The Influence of Cultural Diversity on the Import of China's Core Cultural Products
}

\author{
Hui Fang \\ School of International Economics and Trade \\ Shandong University of Finance and Economics \\ Jinan Shandong Province, China
}

\author{
Meilu Sun*; Ruonan Li \\ School of International Economics and Trade \\ Shandong University of Finance and Economics \\ Jinan Shandong Province, China
}

\begin{abstract}
Based on the model of monopolistic competition in the new trade theory, this paper innovatively analyses the influence mechanism of cultural diversity on the import of Chinese core cultural products. By using the comprehensive measure index of cultural diversity, the paper measures the cultural diversity of China from 2007 to 2015. Then we do an empirical study on the influence of cultural diversity on Chinese cultural products through panel data's random-effects model, and the empirical results show that the cultural diversity of China has been increasing year by year, what's more, it has been playing a positive role in promoting the import of Chinese cultural products. Through the study we can conclude that cultural diversity plays a driving role in cultural trade.
\end{abstract}

Keywords - cultural diversity; the preferences of demand diversity; the import of Chinese cultural product; random-effects model

\section{INTRODUCTION}

Under the environment of global cultural prosperity, the domestic market of China's cultural industry has begun to take shape. In 2016, the value added of China's cultural industry reached 3,078.5 billion yuan, and its share of GDP is $4.14 \%$. China is far from a cultural powerhouse in terms of profits, value added and the share of world market of cultural products, though it is abundant in cultural resource with its long history and rich cultural heritage. So, China is in a disadvantageous position and easily influenced by foreign culture, in the process of cultural exchange. At the same time, because cultural products carry the cultural connotations of a country's unique values, religious beliefs and ways of thinking, consumers are inevitably influenced by the imperceptible influence of foreign cultures when they are exposed to foreign cultural products. Then, with the acceleration of international culture communication and the development of cultural products trade, is the Chinese native culture assimilated by foreign culture or becoming more and more abundant? Is Chinese cultural diversity enhanced or weakened? Dose the change of Chinese cultural diversity impact the import of cultural products in China and how does it work? There's only a small amount of literatures has explained the change of Chinese cultural diversity qualitatively, or indirectly discusses the relationship

The paper is sponsored by the following two projects: Post-funding Project of National Social Science which called Research on Economic Effects of China's Undertaking of International Transfer of Services (The serial number is 13FGL002); Major Project of Social Science Planning Office of Shan Dong Province which called A Study on the Optimization of ODI and Manufacturing Capacity in China: Based on "The 21st Century Maritime Silk Road" (The serial number is 15BJJJ04) between cultural diversity and the trade of cultural products. We begin with a theory model that outlines the influence of cultural diversity on the import of cultural products in China, and then we present an empirical evidence to prove that.

\section{LITERATURE REVIEW}

\section{A. Methods for the measurement of Cultural Diversity}

Quantitative measurements of cultural diversity were first expressed by MacArthur (1965) [1]. He used the number of species of different cultural characteristics of a certain group to measure cultural diversity. Since then some literature works to reflect the cultural diversity of a particular industry by measuring the diversity of representative cultural products. However, the most important feature of cultural diversity is the heterogeneity of culture and the core work of quantitative measurement of cultural diversity is to calculate the degree of differences between different cultural identities. Based on the study of biological diversity, Andrew Stirling (1999) [2] proposed that cultural diversity should include three dimensions: "species number, equilibrium degree and difference". According to this, Andrew Stirling (2007) [3] built a composite index for measuring cultural diversity: $\sum_{i, j} d_{i j} p_{i} p_{j}$. However, the indicator considers only the differences between types $i$ and $j$ but not measure the differences between species $i$ and $j$ with the culture of specific groups when measuring the cultural diversity of specific social groups. In order to address this problem, Benhamou and Peltier (2009) [4] introduced a specific reference type $\mathrm{k}$ and obtained a new indicator $\sum_{i, j} d_{i j} d_{i k} d_{i k} p_{i} p_{j}$ which refined the comprehensive indicator for the quantitative measurement of cultural diversity.

\section{B. Cultural Diversity and Cultural Trade}

The research on the relationship between cultural diversity and cultural trade first appeared in the fields of politics and sociology, while the literature on cultural trade and cultural diversity from the angle of economics is relatively few. Bala \& Van Long (2005) [5] studied the relationship between cultural diversity and cultural trade by using preference selection theory and the extended home market effect model respectively. They believe that communications among countries will bring changes in cultural diversity and increase the market share of cultural products of large countries. In addition, from the point of view of consumer diversity, Saure (2012) [6] held that the 
trade costs of imported products are relatively high and cannot attract consumers. Thus consumers prefer to opt the imports to make them more effective due to the diminishing returns of their original products with the increasing of income level.

It can be seen from the review of relevant literature that current researches on cultural diversity and cultural products mainly include the following characteristics: First, the measurement of cultural diversity is mostly based on data from specific cultural categories and there is little research on the indicators of cultural diversity using the overall cultural product measurement. Secondly, research on the impact of cultural diversity to cultural trade directly is rare. Based on the deficiency of above researches, this paper not only provides new theoretical evidence for the impact of cultural diversity on the import of Chinese cultural products, but also has important significance for the development of Chinese cultural trade.

\section{THEORETICAL ANALYSIS}

Paul Krugman (1985) proposed a general equilibrium model of new trade theory based on the internalization of the product category and the international trade of monopolistic competition, which assumes that economies of scale lie within the manufacturer, and the manufacturer can produce differentiated products without cost. The core cultural products have the tendency of the international monopoly at present, and such tendency exist inside each country. Therefore, we build our paradigm based on the monopolistic competition model of new trade theory.

According to the Multilateral National Monopoly Competition Model, each country and region's preferences for goods consumed in others are different (Gabriel, 2010) [7]. It could be representing as the following formula:

$$
U_{i t}=\sum_{i=1}^{c} \alpha_{\text {cit. }}^{(\sigma-1) / \sigma} \sum_{z=1}^{n_{i t}} m_{z c i t}{ }^{(\sigma-1) / \sigma}
$$

Which $\mathrm{z}$ means the type of consumer goods, $\sigma>1$ means the elasticity of substitution between different core cultural goods, $m_{z c i t}$ indicates the amount of $\mathrm{z}$ commodities $\mathrm{c}$ consumed from i in t year, and $\alpha_{\text {cit }} \geq 0$ represents country C's preference for country I's core cultural goods.

Iceberg Transaction Cost theory suggests that transaction cost will affect trade volume, $t_{\text {cit }} \geq 1$, CIF price (including transition cost) is $p_{\text {cit }}$, and $p_{\text {cit }}$ indicates the price of products from country $\mathrm{C}$ in $\mathrm{t}$ year.

Combined binding condition $\sum_{z=1}^{n_{i t}} p_{z c i t} m_{z c i t}=M_{\text {cit }}$ and maximized the equation (1), calculate the total amount of $M_{c i t}$, imported by country c from country $i$, we conclude that:

$$
M_{\text {cit }}=\left(\frac{\alpha_{\text {cit }}}{t_{\text {cit }}}\right)^{\sigma-1} \mu_{c t} \phi_{i t}
$$

$\mu_{c t}=G_{c t} P_{c t}^{\delta-1}, \phi_{i t}=n_{i t} P_{\mathrm{it}}^{1-\sigma}, \quad(\mathrm{G}$ represents GDP),we can conclude:

$$
P_{i t}=\left[\sum_{i=1}^{c}\left(\frac{\alpha_{c i t}}{t_{c i t}}\right)^{\sigma-1} p_{i t}^{1-\sigma} n_{i t}\right]^{1 /(1-\sigma)}
$$

Considering that the focus of our research is how cultural diversity affects the import of cultural products, we do not have to pay attention to the equilibrium condition of the model. We just need to validate the ways in which cultural differences affect core trade in cultural goods. According to the equation (2) above, there are two main channels for the impact of cultural diversity on trade flows.

First is the cost of trade. Because of the existence of cultural diversity, cultural distance also exists, which will enhance the transaction costs of foreign trade, thus reducing the profits of exporters and reduce the import of cultural trade.

Second is the preference of consumer. Cultural diversity leads to product diversity, which may have a potential impact on the amount of cultural trade imports in turn because different consumers' preference for different cultural commodities.

In addition to cultural factors, some traditional economic and geographical factors will also affect the cost of trade: (1) transport costs, which is measured as geographical distance;(2) trade policies, which is measured as a dummy variable that takes a value of 1 if they are members of free trade agreements, and 0 otherwise; (3) the level of application of science and technology, which controls for composite index of internet usage and mobile telephone usage. Moreover, according to equation (2) above, the total imports products are also affected by the import price of the product and GDP of importing country.

In the next content, we provide empirical evidence with an regression model based on the conclusion of the theoretical analysis.

\section{EMPIRICAL TESTS}

\section{A. Measurement of Chinese Cultural Diversity}

To objectively investigate the development of Chinese cultural diversity, we collect the data of Chinese copyright import from 9 sample countries from 2007 to 2015, such as the United States, the United Kingdom, Germany, France, Russia, Canada, Singapore, Japan, and Korea. Using the data we quantitatively measure the degree of Chinese cultural diversity through the comprehensive indicator $\sum_{i, j} d_{i j} d_{i k} d_{i k} p_{i} p_{j}$ put forward by Benhamou and Peltier(2009).

\section{1) The measurement of equilibrium degree " $p$ "}

We choose seven types of copyright from sample countries, and the following is the degree of equilibrium "p" (see Table I). 
TABLE I.

THE SHARE OF COPYRIGHTS IMPORTED FROM SAMPLE COUNTRIES FROM 2007 TO 2015(\%)

\begin{tabular}{|c|c|c|c|c|c|c|c|c|c}
\hline Year & $\mathbf{2 0 0 7}$ & $\mathbf{2 0 0 8}$ & $\mathbf{2 0 0 9}$ & $\mathbf{2 0 1 0}$ & $\mathbf{2 0 1 1}$ & $\mathbf{2 0 1 2}$ & $\mathbf{2 0 1 3}$ & $\mathbf{2 0 1 4}$ & $\mathbf{2 0 1 5}$ \\
\hline 1 USA & 51.2 & 47.6 & 43.6 & 45.2 & 42.3 & 39.5 & 40.2 & 42.8 & 40.7 \\
2 UK & 21.0 & 19.5 & 18.9 & 18.0 & 19.5 & 19.8 & 19.7 & 18.6 & 21.2 \\
3 Germany & 5.4 & 7.7 & 6.4 & 6.8 & 5.9 & 6.8 & 6.8 & 5.3 & 6.3 \\
4 France & 4.7 & 4.8 & 5.0 & 4.0 & 5.9 & 5.5 & 6.1 & 5.4 & 5.8 \\
5 Russia & 0.6 & 1.1 & 0.6 & 0.8 & 0.5 & 0.4 & 0.4 & 0.6 & 0.7 \\
6 Canada & 0.7 & 0.5 & 0.8 & 0.8 & 0.9 & 1.1 & 1.0 & 0.8 & 1.2 \\
7 Singapore & 2.5 & 2.8 & 3.1 & 3.8 & 2.7 & 2.0 & 2.1 & 2.3 & 1.6 \\
8 Japan & 8.8 & 10.7 & 13.0 & 12.5 & 14.1 & 16.5 & 14.9 & 13.1 & 13.3 \\
9 Korea & 5.2 & 5.3 & 8.5 & 8.0 & 8.2 & 8.4 & 8.8 & 11.2 & 9.1 \\
\hline
\end{tabular}

TABLE II. DEGREE OF CULTURAL DIFFERENCES AMONG SAMPLE COUNTRIES

\section{2) The measurement of difference " $\mathrm{d}_{\mathrm{ii}}$ "}

We choose Hofstede's (1991)"cultural dimension theory" and Jianhong Qi's (2012) [8] method to calculate the cultural distance index:

$$
d_{i j}=\left\lceil\frac{\sum_{k=1}^{6}\left(I_{i k}-I_{j k}\right)^{2}}{V_{k}}\right\rceil / 6
$$

$I_{i k}$ indicates the score of country $\mathrm{i}$ in the $\mathrm{k}$ cultural dimension, $I_{j k}$ indicates the score of country $\mathrm{j}$ in the $\mathrm{k}$ cultural dimension, $V_{k}$ indicates the variance of the $\mathrm{k}$ dimension in all the sample countries. The formula is used to calculate the cultural distance between every two countries, that is the degree of cultural difference between different countries and China: $d_{i j}, d_{i k}, d_{j k}$ (see Table II).

\begin{tabular}{c|c|c|c|c|c|c|c|c|c}
\hline & CHN & USA & GBR & GER & FRA & RUS & CAN & SIN & JPN \\
\hline 1USA & 3.7 & & & & & & & & \\
2GBR & 3.12 & 0.22 & & & & & & & \\
3GER & 1.59 & 1.51 & 0.97 & & & & & & \\
4FRA & 1.87 & 1.48 & 1.53 & 0.94 & & & & & \\
5RUS & 1.42 & 4.45 & 4.42 & 2.33 & 0.96 & & & & \\
6CAN & 3.24 & 0.11 & 0.22 & 1.22 & 1.07 & 3.75 & & & \\
7SIN & 0.58 & 2.66 & 2.23 & 1.86 & 1.68 & 2.05 & 2.1 & & \\
8JPN & 1.72 & 2.88 & 2.31 & 0.83 & 1.85 & 2.74 & 2.78 & 2.86 & \\
9KOR & 1.17 & 4.09 & 3.57 & 1.33 & 1.14 & 0.68 & 3.2 & 1.58 & 2 \\
\hline
\end{tabular}

3) Measurement of the composite index of cultural diversity

Based on the calculations above, the sub-indices of the composite index have been given, then we calculate the comprehensive index of Chinese cultural diversity from 2007 to 2015(see Table III).

TABLE III. COMPREHENSIVE INDEX OF CULTURAL DIVERSITY IN CHINA

\begin{tabular}{c|c|c|c|c|c|c|c|c|c|}
\hline Year & $\mathbf{2 0 0 7}$ & $\mathbf{2 0 0 8}$ & $\mathbf{2 0 0 9}$ & $\mathbf{2 0 1 0}$ & $\mathbf{2 0 1 1}$ & $\mathbf{2 0 1 2}$ & $\mathbf{2 0 1 3}$ & $\mathbf{2 0 1 4}$ & $\mathbf{2 0 1 5}$ \\
\hline $\begin{array}{c}\text { Cultural } \\
\text { diversity }\end{array}$ & 2.88 & 3.14 & 3.43 & 3.37 & 3.48 & 3.59 & 3.55 & 3.61 & 3.50 \\
\hline
\end{tabular}

The change in cultural diversity is a rising trend, which shows that Chinese culture still behave very well under the influence of the trend of globalization and the impact of foreign culture.

\section{B. Econometric model and variable description}

According to the theoretical analysis, there's virtual variables exist in the control variables, so the random effect model of panel data is adopted. In addition, in order to eliminate the dimension, the logarithm of the variables except the virtual variables is taken as follows:

$$
\begin{aligned}
\ln X_{c j t}=\beta_{0} & +\beta_{1} \ln C D_{c t}+\beta_{2} \ln Y_{j t}+\beta_{3} \ln y_{c t}+\beta_{4} \ln D_{c j} \\
& +\beta_{5} \ln T_{j t}+\beta_{6} F T A_{c j}+\beta_{7} B O R_{c j}+v_{j}+\varepsilon_{c j t}
\end{aligned}
$$

1) Dependent variable

The dependent variable for our empirical tests is the import amount of core cultural products $\left(\ln X_{c j t}\right)$, which is measured as China's core cultural products import from country $\mathrm{j}$ in year $\mathrm{t}$, and the primary data source is United Nations Commodity Trade Database (UNCOMTRADE). We selected and classified core cultural products based on SITC4.0 according to the International Movement of Cultural goods and Services 2004-2013 published by UNESCO.

\section{2) Independent variable}

The independent variable for our study is the cultural diversity and is denoted by $\ln C D_{c t}$, which is measured by China's cultural diversity in year $t$ and calculated from the comprehensive measurement $\sum_{i, j} d_{i j} d_{i k} d_{i k} p_{i} p_{j}$ by the theoretical analysis above. The data source that we used to measure the level of equilibrium is the Statistical Yearbook of China's Tertiary Industry 2007-2015, and cultural distance date from Hofsteinde's official website.

\section{3) Control variable}

Exporting country's GDP level $\left(\ln Y_{j t}\right)$ controls for the size and level of development of the exporting country in year $t$. Considering that the availability of data and the focus of this paper is on the trade of cultural products which belongs to the tertiary industry, we use the added value of items such as services as proxy, which sources from World Bank Database.

Per capita national income of China $\left(\ln Y_{c t}\right)$ controls for the purchasing power level of Chinese consumers in year $t$. We got the per capita GNI data from the World Bank database.

Transportation cost $\left(\ln D_{c j}\right)$ is included to control the transportation cost between the exporting country and China, which is measured as the product of the shortest transportation 
distance between the two capitals and international oil price. The corresponding data are derived from the world ATLAS Database and the International Monetary Fund (IMF).

The level of communication $\left(\ln T_{j t}\right)$ controls for the close degree of communication. We measure this indicator by the square root of the product of each hundred Internet user and the number of mobile phones per hundred people. The corresponding data are derived from the World Development report.

We also include two dummy variables $F T A_{c j}$ and $B O R_{c j}$ to control the impact of Free Trade Areas, Free Trade Agreements, and the state bordering on each other. We assign value for $F T A_{c j}$ based on whether the country has been built or negotiated Free Trade Areas or Free Trade Agreements with China. Therefore, the value of Singapore, Japan and Korea is 1 , and 0 for others. Similarly, the value of $B O R_{c j}$ is 1 means the country borders China on land or sea adjacent, so Russia, Japan, South Korea's assignment is 1 , and the other countries are 0 .

\section{Analysis of the measurement results}

Table IV, column 2, reports the results of mixed regression with cluster robust standard errors: all the variables are significant, which shows that the selected control variables are meaningful. However, because the data selected in this paper are panel data, and there is virtual variables here, so we choose the random influence variable intercept model and the result is showed in column 2-4 of Table IV.

TABLE IV. REGRESSION RESULTS

\begin{tabular}{|c|c|c|c|c|}
\hline & $\begin{array}{c}\text { Mixed regression } \\
\text { (clustering robust } \\
\text { standard error) }\end{array}$ & $\begin{array}{l}\text { Random } \\
\text { effect(1) }\end{array}$ & $\begin{array}{l}\text { Random } \\
\text { effect(2) }\end{array}$ & $\begin{array}{l}\text { Random } \\
\text { effect(3) }\end{array}$ \\
\hline $\begin{array}{c}\ln C D_{c i} \\
{\left[\beta_{1}\right]}\end{array}$ & $\begin{array}{c}4.405^{* * * *} \\
(1.205)\end{array}$ & $\begin{array}{l}1.812 * * \\
(0.759)\end{array}$ & $\begin{array}{c}0.972 * * \\
(0.397)\end{array}$ & $\begin{array}{c}1.013^{* * * *} \\
(0.387)\end{array}$ \\
\hline $\begin{array}{l}\ln Y_{i t} \\
{\left[\beta_{2}\right]}\end{array}$ & $\begin{array}{c}0.927 * * * \\
(0.156)\end{array}$ & $\begin{array}{c}0.599 * * * \\
(0.197)\end{array}$ & $\begin{array}{c}0.526^{* *} \\
(0.224)\end{array}$ & $\begin{array}{c}0.393 \\
(0.223)\end{array}$ \\
\hline $\begin{array}{l}\ln y_{c t} \\
{\left[\beta_{3}\right]}\end{array}$ & $\begin{array}{c}0.115^{*} \\
(0.324)\end{array}$ & $\begin{array}{c}0.463 \\
(0.315)\end{array}$ & $\begin{array}{l}0.642 * \\
(0.351)\end{array}$ & $\begin{array}{c}0.654^{*} \\
(0.360)\end{array}$ \\
\hline $\begin{array}{c}\ln D_{c i} \\
{\left[\beta_{4}\right]}\end{array}$ & $\begin{array}{c}-0.909 * * \\
(0.316)\end{array}$ & $\begin{array}{c}-0.222 \\
(0.154)\end{array}$ & & $\begin{array}{c}-0.747 * * * \\
(0.287)\end{array}$ \\
\hline $\begin{array}{l}\ln T_{j t} \\
{\left[\beta_{5}\right]}\end{array}$ & $\begin{array}{c}-2.275^{* *} \\
(0.696)\end{array}$ & $\begin{array}{c}-1.552^{* * * *} \\
(0.165)\end{array}$ & $\begin{array}{c}-1.517 * * * \\
0.152\end{array}$ & $\begin{array}{c}-1.471 \text { *** } \\
(0.159)\end{array}$ \\
\hline $\begin{array}{c}F T A_{c i} \\
{\left[\beta_{6}\right]}\end{array}$ & $\begin{array}{c}3.578 * * * \\
(0.410)\end{array}$ & $\begin{array}{c}3.704 * * * \\
(0.470)\end{array}$ & $\begin{array}{c}3.831 * * * \\
0.551\end{array}$ & $\begin{array}{c}3.530 * * * \\
(0.544)\end{array}$ \\
\hline $\begin{array}{c}B O R_{e i} \\
{\left[\beta_{7}\right]}\end{array}$ & $\begin{array}{c}-3.475^{* * *} \\
(0.413)\end{array}$ & $\begin{array}{c}-2.644 * * * \\
(0.363)\end{array}$ & $\begin{array}{c}-2.438 * * * \\
0.392\end{array}$ & $\begin{array}{c}-1.851 * * * \\
(0.520)\end{array}$ \\
\hline$R^{2}$ & 0.8731 & & & \\
\hline
\end{tabular}

Note:(1) the parentheses below the estimation coefficient are standard errors, and the asterisk indicates the level of significance, that is, $* \mathrm{P}<0.10,{ }^{* *} \mathrm{P}<0.05$, ${ }^{* * *} \mathrm{P}<$ 0.01 .

We do our analysis base on Random effect (1), which showed in column 3 of Table IV. The coefficient of cultural diversity is significant at the level of 0.05 , which means that under the influence of consumers' preference for diversity of demand with the improvement of domestic cultural diversity, China's import quantity of core culture products will increase due to the enhance of Chinese cultural diversity. Except per capita national income and geographical distance, the other control variables are significant at the level of 0.05 . From this, it can be concluded that China tends to import cultural products from countries with developed domestic cultural industries. It also explains why the import of cultural products such as music and films from Europe and the United States increase continuously. The application of information technology promotes cultural communication between two countries and reduces the cost of information searching, and it played a positive role in the China's import of cultural products. Trade facilitation is enhanced by the signing of FTA agreements, thus imports will increase. What's more, the coefficient of the virtual variable BOR is negative and significant at the level of 0.01 , the reason is, the closer the country is, the more similar its culture is. Given the consumer's preference of diversity, it will reduce China's imports of cultural products from neighbor countries.

In random effect (2), the control variable of geographical distance $\ln D_{c j}$ is removed; the explanatory variables and all the control variables are significant. In random effect (3), the original geographical distance is used to explain geographical distance and all control variables are significant.

\section{CONCLUSION}

\section{A. Conclusions}

1) In the sample period,the degree of cultural diversity in China showed an upward trend.It indicating that Chinese culture can survival and develop, and it is becoming richer and more diverse in the "a hundred flowers blossom, a hundred schools of thought" contend of the world after being integrated into the trend of globalization.

2) The change of cultural diversity has a significant positive effect on the import of core cultural products.It shows that because of the promotion of cultural diversity in our country, the demand of different cultural products of our people has increased. Thus, the products provided by the domestic cultural industry alone no longer meet the diversity preferences of consumers, import of cultural products gets necessary.

\section{B. Illuminations}

Chinese culture is inclusive and adaptable. Economic globalization will not cause the simplification and homogenization of Chinese culture. Therefore restrictions on the trade of cultural products and exclusion of foreign cultures will not eliminate the adverse effect of foreign culture, on the contrary, these practices will impede the interaction, competition and integration between different cultures, hinder the inheritance, innovation and spread of Chinese culture. With the enrichment of cultural connotation, Chinese culture is becoming more accepting and more tolerant, so the cost 
caused by cultural difference is becoming lower, then the cultural trade in China is developing rapidly.

\section{REFERENCES}

[1] MacArthur R. Patterns of species diversity. Biol Rev, 1965, 40: 510-533.

[2] Andrew Stirling. The appraisal of sustainability: Some problems and possible responses[J]. Local Environment. 1999(2).

[3] Andrew Stirling. A General Framework for Analyzing Diversity in Science, Technology and Society[J]. SPRU Electronic Working Paper Series, 2007.
[4] Francoise Benhamou, Stephanie Peltier. Diversity Analysis in Cultural Economics: Theoretical and Empirical Consideration[J]. Group de Recherche Angevin en Economie et Management, 2009, 1-26.

[5] Bala V, Van Long N. International Trade and Cultural Diversity with Preference Selection[J]. European Journal of Political Economy 1, 2005.

[6] Saure, Bounded Love of Variety and Patterns of Trade, Open Economies Review4, 2012, 645 674.

[7] Gabriel J. Felbermayr, Farid Toubal. Cultural Proximity and Trade[J]. European Economic Review. 2012, 54(2):279-293.

[8] Jianhong Qi, Li Li, and Li Yang. Location Selection of China's OFDI: Threshold Effect and Inspection Based on Cultural Distance [J]. Journal of International Trade. 2012(12):137-147. In Chinese. 